\title{
Broadband and Dual Band Modified Rectangular Microstrip Antennas
}

\author{
Amit A. Deshmukh \\ EXTC, DJSCOE \\ Vile - Parle (W), \\ Mumbai, India
}

\author{
Rakesh Jondhale \\ EXTC, DJSCOE \\ Vile - Parle (W), \\ Mumbai, India
}

\author{
Ishitva Ajmera \\ EXTC, DJSCOE \\ Vile - Parle (W), \\ Mumbai, India
}

\begin{abstract}
The more frequently used technique to realize broadband and dual band microstrip antenna is by cutting the slot at an appropriate position inside the patch. In this paper, an in-depth analysis of dual band rectangular slot cut rectangular microstrip antenna and plus shaped slot cut broadband rectangular microstrip antenna is presented. The dual band slot cut antenna is reported to be resonant at 3640 and 4080 MHz. Through the analysis it was observed that the slot modifies the resonance frequencies of $\mathrm{TM}_{11}$ and $\mathrm{TM}_{02}$ mode of the rectangular patch and optimizes the impedance at them to realize dual frequency response. Further when an additional horizontal slot is cut inside the above rectangular slot which realizes plus shaped slot, it further reduces $\mathrm{TM}_{02}$ mode resonance frequency and along with the $\mathrm{TM}_{11}$ patch mode, yields broadband response. The proposed analysis gives an insight into the functioning of the slot cut patch antennas operating at higher order modes as well as it will help them in designing them in given frequency band.
\end{abstract}

\section{Keywords}

Rectangular Microstrip Antenna, Dual band microstrip antenna, Broadband microstrip antenna, Rectangular slot, Plus shaped slot, Higher order mode

\section{INTRODUCTION}

The simplest method to realize broadband microstrip antenna (MSA) on thinner substrates (i.e. thickness $<0.03 \lambda_{0}$ ), is by using multi-resonator gap-coupled or stacked configurations [1 - 3]. In this method, parasitic MSA having slightly different resonance frequency than the fed MSA is either gapcoupled to the fed patch or electromagnetically coupled to fed patch by stacking it on top of it. Due to the coupling between the fed and parasitic patch modes, a loop is formed inside the VSWR $=2$ circle in the smith chart, resulting in broader bandwidth (BW). The dual frequency response is realized when the coupling between the two modes is larger, that results in larger loop size in the smith chart, which does not lie completely inside the VSWR $=2$ circle [1]. However this multi-resonator technique increases the total antenna size. By maintaining the same antenna size, broadband or dual band MSA is realized by cutting the slot of different shapes like, Uslot, V-slot, rectangular slot, step slot, tooth-brush shaped slot, etc, at an appropriate position inside the patch [4-10]. The dual polarized dual or multi-band (i.e. triple or four band response) MSA is realized by placing the feed point along the diagonal axis inside the slot cut patch or by cutting a single slot inside the patch thereby realizing asymmetrical configuration [4].
While designing slot cut dual or broadband MSAs, it is a general understanding that slot introduces an additional mode near the fundamental patch mode when its length either equals half wave or quarter wave in length. However the recent study on the broadband or dual band slot cut MSAs shows that slot modifies/reduces the resonance frequencies of higher order orthogonal modes of the patch and along with fundamental patch mode, yields broadband or dual band response [11]. The slot also modifies the surface current distribution at higher order orthogonal modes and aligns them in the same direction as that of the currents at fundamental patch mode. Thereby it yields broadside radiation pattern over the complete $\mathrm{BW}$ or at the dual frequencies, without any variations in the directions of principle planes. In most of the reported and studied slot (rectangular slot or U-slot) cut configurations, broadband or dual band response was realized with respect to fundamental patch mode. Recently by cutting rectangular slot or plus shaped slot on one of the edges of rectangular MSA (RMSA), a dual band or broadband RMSA has been realized [12]. The said configurations were reported to be functioning around $\mathrm{TM}_{11}$ mode frequency of equivalent RMSA and slots are reported to introduce a mode near $\mathrm{TM}_{11}$ mode frequency. The dual band RMSA operates at frequencies of 3614 and 4076 $\mathrm{MHz}$, with BW of 132 and $113 \mathrm{MHz}$, respectively, whereas broadband RMSA yields BW of $270 \mathrm{MHz}$ (7.4\%).

In this paper, to understand the functioning of reported slot cut RMSAs, an in-depth analysis of dual band rectangular slot cut and broadband plus shaped slot cut RMSAs is presented. The resonance curve plots, surface currents distributions generated using IE3D software were separately studied for equivalent RMSA and slot cut RMSAs for varying slot dimensions [13]. The rectangular slot in dual band RMSA reduces the $\mathrm{TM}_{11}$ mode resonance frequency and optimizes the impedance at the same, to yield dual frequency response with respect to $\mathrm{TM}_{02}$ mode frequency of RMSA. The position of the offset feed in the slot cut patch helps in optimizing the input impedance at both the modified modes. The surface currents at $\mathrm{TM}_{11}$ mode varies along patch length and width whereas that at modified $\mathrm{TM}_{02}$ mode, they vary along patch width and shows two half wavelength variations. Hence the radiation pattern at first frequency is broadside whereas that at second frequency it is conical, i.e. maximum in the end-fire direction. Further to realize broadband response an additional horizontal slot is cut in the center of above rectangular slot, which realizes plus shaped slot. The addition of second horizontal slot reduces $\mathrm{TM}_{02}$ mode frequency of RMSA, such that the loop formed due to the coupling between modified $\mathrm{TM}_{11}$ and $\mathrm{TM}_{02}$ modes lies inside VSWR $=2$ circle, in the smith chart, to yield broader BW. Since the surface currents at modified $\mathrm{TM}_{11}$ and $\mathrm{TM}_{02}$ modes are varying along horizontal and vertical directions inside the patch, the radiation pattern shows higher 
cross polarization levels. Further based on the above concept of operating dual and broadband RMSAs around $\mathrm{TM}_{11}$ mode resonance frequency, rectangular slot and plus shaped slot cut RMSAs in $1000 \mathrm{MHz}$ frequency band are proposed. The dual band RMSA operates at frequencies of 1632 and $1827 \mathrm{MHz}$ with BW of 40 and $41 \mathrm{MHz}$, respectively. The broadband RMSA yields BW of nearly $100 \mathrm{MHz}$ at center frequency of around $1640 \mathrm{MHz}$. Thus the proposed analysis explains and presents the designs of dual band and broadband slot cut RMSAs with respect to higher order $\mathrm{TM}_{11}$ mode frequency of equivalent RMSA.

\section{DUAL BAND AND BROADBAND RMSAs}

The reported dual band rectangular slot cut RMSA is shown in Fig. 1(a) [12]. The equivalent RMSA is fabricated on FR4 substrate having parameters, $\varepsilon_{\mathrm{r}}=4.4, \mathrm{~h}=0.159 \mathrm{~cm}$ and $\tan \delta$ $=0.025$. For equivalent RMSA dimensions, the patch resonates at its $\mathrm{TM}_{11}$ mode frequency of around $4060 \mathrm{MHz}$. Its calculated frequency using resonance frequency equation is $3980 \mathrm{MHz}$ [1]. For $\mathrm{l}_{1}=1.38 \mathrm{~cm}$ and $\mathrm{w}=0.05 \mathrm{~cm}$, rectangular slot cut dual band RMSA operates at dual frequencies of 3640 and $4080 \mathrm{MHz}$, with VSWR BW of 2.8 and $2.45 \%$, respectively, as shown in Fig. 1(a, b) [12]. The dual band response is reported due to the excitation of additional mode near the $\mathrm{TM}_{11}$ mode frequency of the equivalent RMSA. Since the BW at above dual frequencies is less than $3 \%$, to increase the $\mathrm{BW}$, an additional horizontal slot is cut in the center of above rectangular slot as shown in Fig. 1(c), which realizes plus shaped slot. This configuration yields BW of 270 $\mathrm{MHz}(7.4 \%)$ which is more than twice the $\% \mathrm{BW}$ as that obtained at individual frequencies of dual band slot cut RMSA. However in above dual band as well as broadband RMSAs an explanation for the mode introduced by the slots is not given. Therefore to understand the dual and broadband response, an analysis of slot cut RMSAs is carried out as discussed below.

\section{ANALYSIS OF DUAL BAND AND BROADBAND RMSAS}

The dimensions of equivalent RMSA in above configurations are, $\mathrm{L}=3.429 \mathrm{~cm}$ and $\mathrm{W}=2.07 \mathrm{~cm}$, which gives aspect ratio $(\mathrm{L} / \mathrm{W})$ of 1.66. The larger ratio will realize higher gain but will also lead to closely spaced orthogonal frequencies. In the reported configuration, the larger patch dimension (L) is oriented along $\mathrm{Y}$-axis and hence the dominant patch mode is $\mathrm{TM}_{01}$. For FR4 substrate, various resonance frequencies of RMSA calculated by using its resonance frequency equation are, $\mathrm{f}_{\mathrm{TM} 01}=1941 \mathrm{MHz}, \mathrm{f}_{\mathrm{TM} 10}=3098 \mathrm{MHz}, \mathrm{f}_{\mathrm{TM} 11}=3659 \mathrm{MHz}$, $\mathrm{f}_{\mathrm{TM} 02}=3883 \mathrm{MHz}, \mathrm{f}_{\mathrm{TM} 20}=6195 \mathrm{MHz}, \mathrm{f}_{\mathrm{TM} 12}=4967 \mathrm{MHz}$ and $\mathrm{f}_{\mathrm{TM} 21}=6492 \mathrm{MHz}$. The equivalent RMSA is simulated for feed point location at $\mathrm{x}_{\mathrm{f}}=0.3 \mathrm{~cm}$ and $\mathrm{y}_{\mathrm{f}}=1.3 \mathrm{~cm}$, as shown in Fig. 2(a) and its input impedance and resonance curve plots are shown in Fig. 2(b, c). The input impedance plot shows the formation of loop whereas resonance curve shows peaks due to $\mathrm{TM}_{01}(2031 \mathrm{MHz}), \mathrm{TM}_{10}(3224 \mathrm{MHz}), \mathrm{TM}_{11}(3895 \mathrm{MHz})$ and $\mathrm{TM}_{02}(4045 \mathrm{MHz})$ modes. The loop is formed due to the close proximity of $\mathrm{TM}_{11}$ and $\mathrm{TM}_{02}$ modes. In [12] it is reported that circular polarization is realized at the frequencies where loop is present. However simulated axial ratio in broadside as well as end-fire direction was found to be more than $20 \mathrm{~dB}$. Further surface current distribution at $\mathrm{TM}_{11}$ and $\mathrm{TM}_{02}$ modes are shown in Fig. 2(d, e).

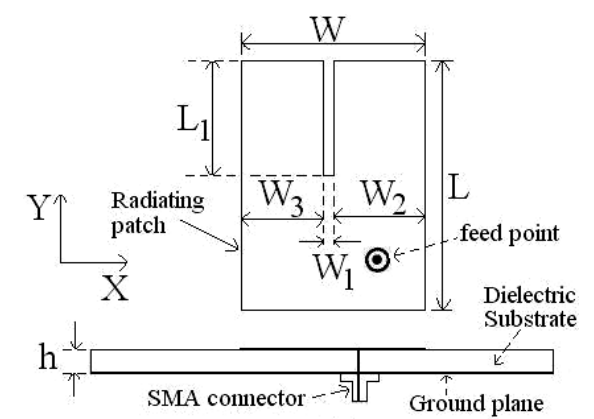

(a)
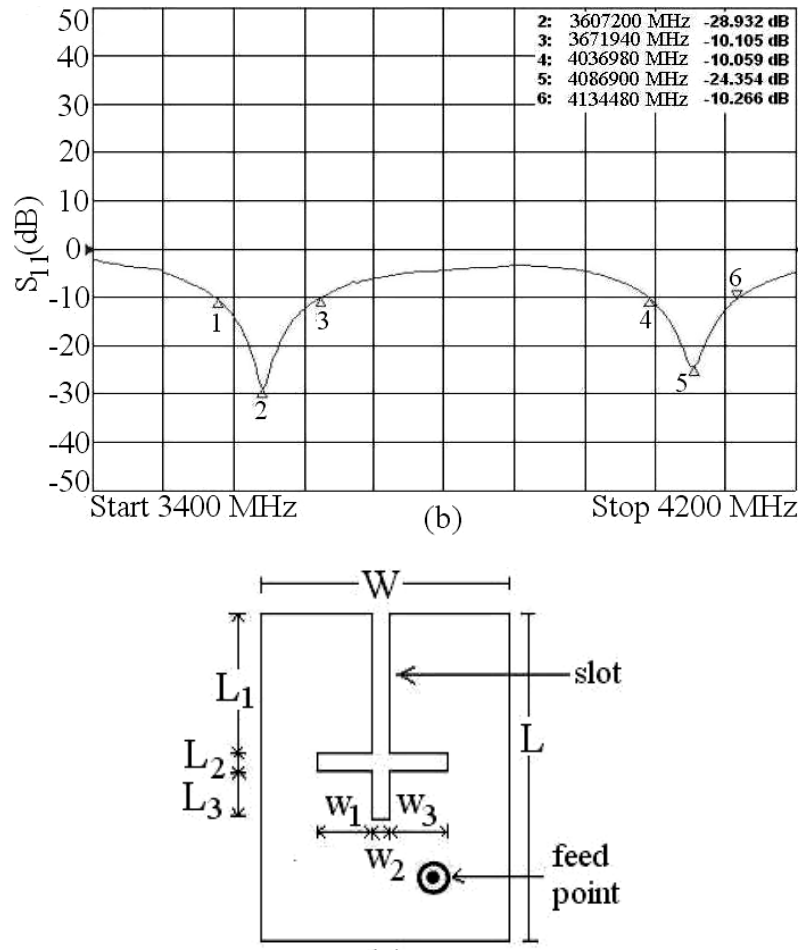

(c)

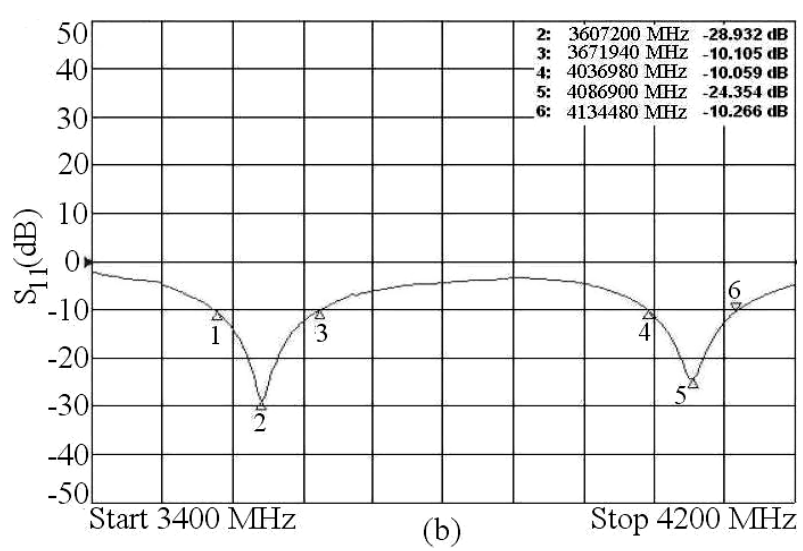

Fig. 1 (a) Dual band slot cut RMSA, its (b) return loss $\left(\mathbf{S}_{11}\right)$ plot (c) broadband plus shaped slot cut RMSA and its (d) return loss plot [12] 


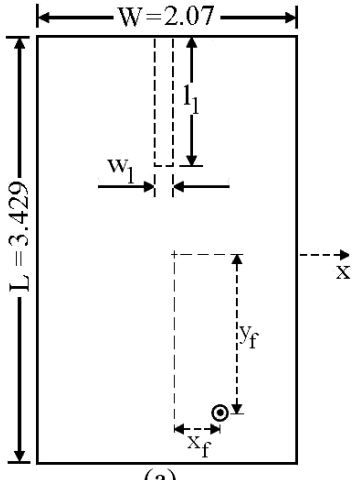

(a)

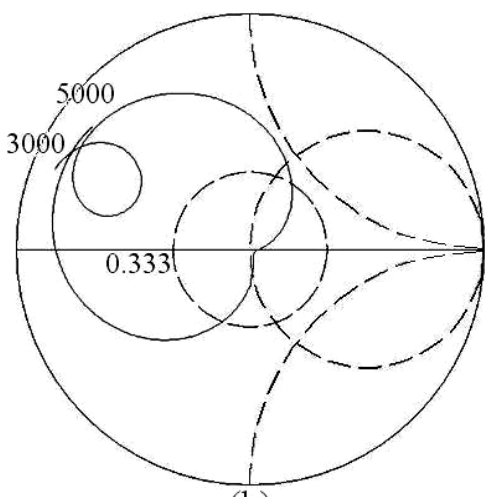

(b)
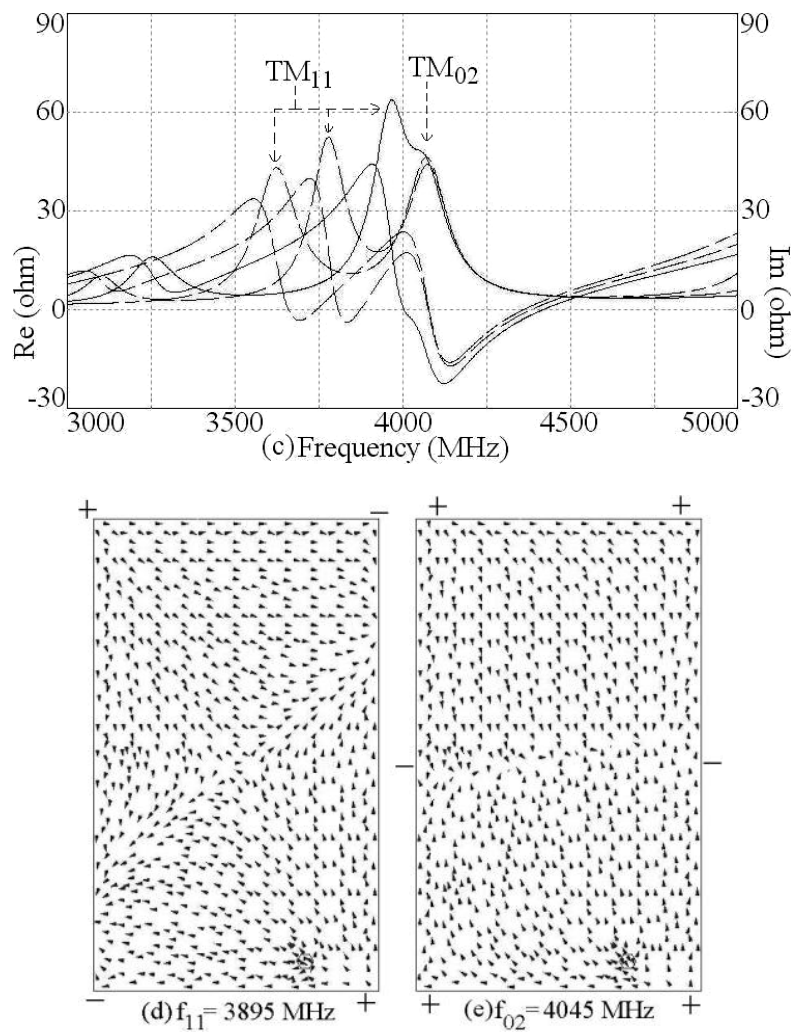

Fig. 2 (a) Dual band slot cut RMSA, (b) input impedance plot for RMSA (c) resonance curve plot for (-) RMSA and for $(--) l_{1}=0.5,(--\square) l_{1}=1.0$ and $(d, e)$ surface current distribution at two modes for RMSA

At $\mathrm{TM}_{11}$ mode, currents show one half wavelength variations along patch length and width. At $\mathrm{TM}_{02}$ mode, current shows two half wavelength variations along patch width. To realize dual band RMSA, rectangular slot is cut inside the patch as shown in Fig. 2(a) and resonance curve plots for varying ' $l_{1}$ ' and ' $w_{1}$ ' $=0.5 \mathrm{~cm}$, is shown in Fig. 2(c). The slot length is orthogonal to the surface currents at $\mathrm{TM}_{11}$ mode and hence with an increase in ' $l_{1}$ ' its frequency reduces. The $\mathrm{TM}_{02}$ mode frequency nearly remains constant as slot length is parallel to its surface currents. Thus slot length tunes the $\mathrm{TM}_{11}$ mode frequency with respect to $\mathrm{TM}_{02}$ mode to realize dual band response. For $1_{1}=1.38 \mathrm{~cm}$, simulated dual frequencies and BW's are, 3614 and $4076 \mathrm{MHz}$ and 132 and $113 \mathrm{MHz}$, respectively as shown in Fig. 3(a). The simulated surface current distributions at dual frequencies and radiation pattern at them is shown in Fig. 3(b-e).

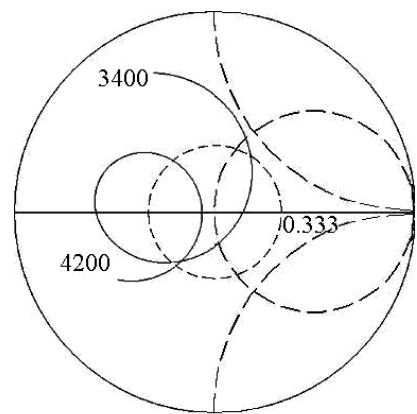

(a)
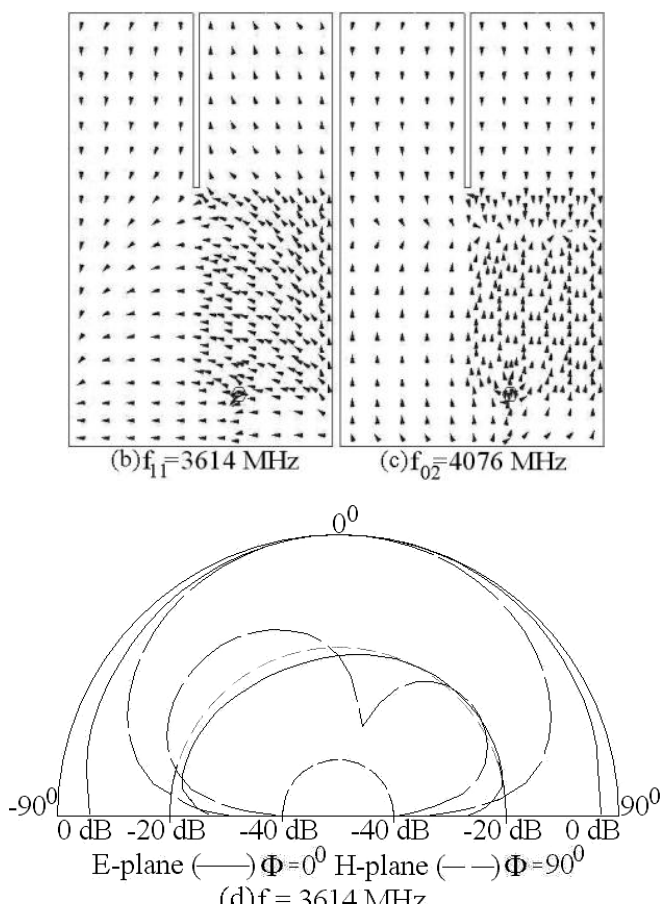

(d) $\mathrm{f}=3614 \mathrm{MHz}$

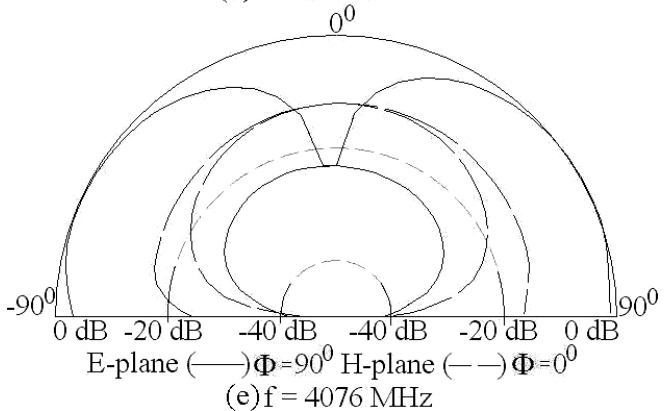

Fig. 3 (a) Input impedance plot, (b, c) Surface current distributions and (d, e) simulated radiation patterns at dual frequencies for dual band rectangular slot cut RMSA 
The surface currents at first frequency are predominantly present along horizontal direction inside the slot cut patch. The surface currents which are oppositely directed along patch width cancels their radiation in the broadside direction. Hence the radiation pattern at first frequency is in the broadside direction with E-plane directed along $\Phi=0^{0}$. At second frequency, since the currents are directed along patch width and shows two half wavelength variations along the same, the radiation pattern is conical, i.e. maximum in the end-fire direction. The pattern shows higher cross-polarization levels. Further to realize broadband response, inside this rectangular slot cut RMSA, a horizontal slot is cut as shown in Fig. 4(a). This realizes plus shaped slot and resonance curve plot for varying slot lengths ' $l_{2}$ ' are shown in Fig. 4(b). The horizontal slot is orthogonal to the surface currents at $\mathrm{TM}_{02}$ mode and therefore it reduces its resonance frequency.

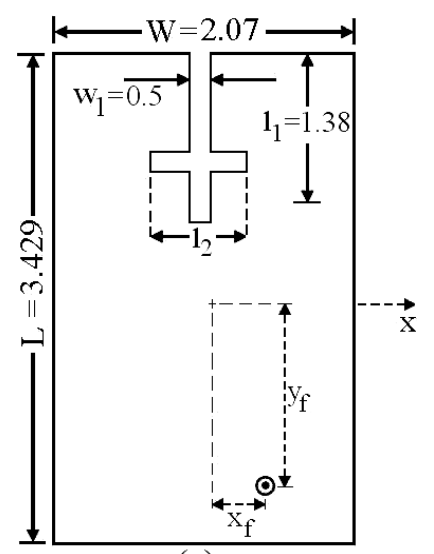

(a)

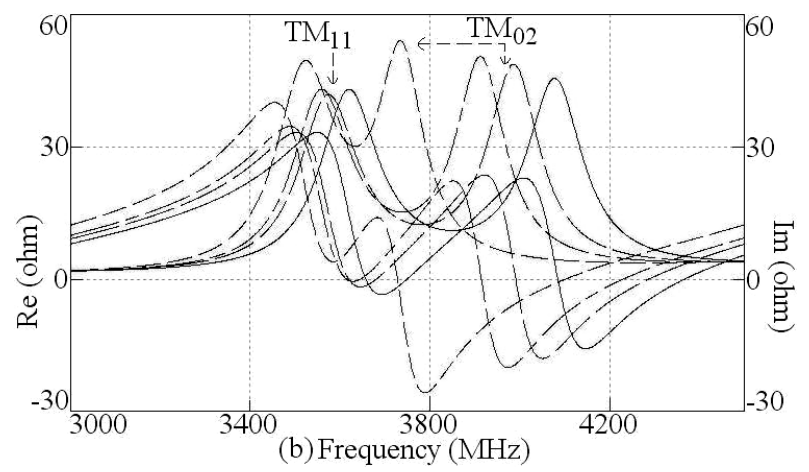

Fig. 4 (a) Plus shaped slot cut RMSA and its (b) resonance curve plots for $\left.\mathrm{l}_{2}=(-) 0,(--) 0.6,(---) 0.8,(--)\right) 1.1$

Further the slot also optimizes $\mathrm{TM}_{11}$ mode frequency as well as the input impedance at $\mathrm{TM}_{11}$ and $\mathrm{TM}_{02}$ modes. This realizes loop formed due to coupling between these modes inside VSWR $=2$ circle, to realize broadband response as shown in Fig. 5(a). The realized simulated BW is $270 \mathrm{MHz}$ $(7.4 \%)$ which is very close to the reported value. The surface current distribution over the BW for plus shaped slot cut RMSA is shown in Fig. 5(b-d). At first frequency the surface currents varies along horizontal direction (modified $\mathrm{TM}_{11}$ mode), which leads to radiation pattern in broadside direction with E-plane aligned along $\Phi=0^{0}$. At second frequency, surface currents shows variation along patch length as well as width, due to the proximity of modified $\mathrm{TM}_{11}$ and $\mathrm{TM}_{02}$ modes. At third frequency, currents are varying along patch width due to $\mathrm{TM}_{02}$ mode. Therefore at centre frequency and towards the higher frequencies of the $\mathrm{BW}$, radiation pattern shows conical radiation (i.e. maximum in the end-fire direction) with higher cross polarization levels. Thus the dual band and broadband response is due to the coupling between modified $\mathrm{TM}_{11}$ and $\mathrm{TM}_{02}$ modes.

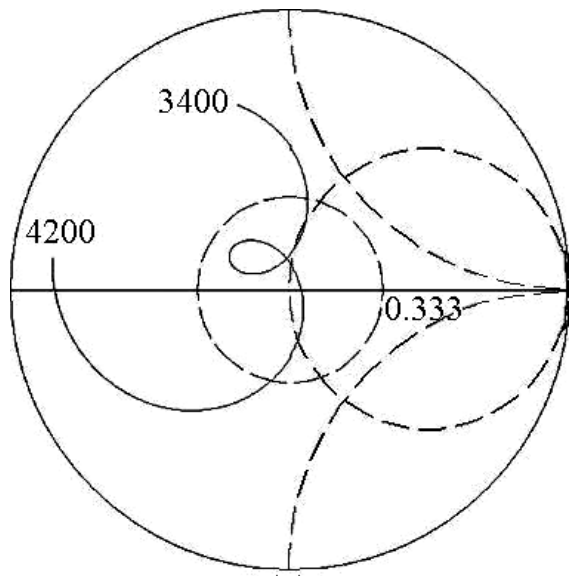

(a)

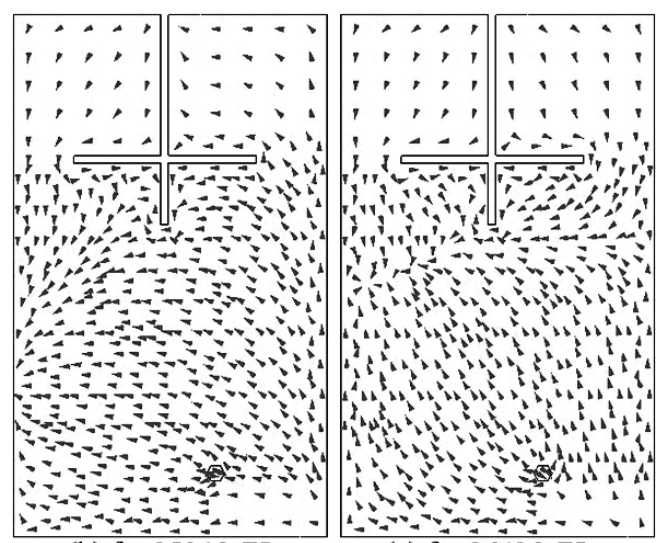

(b) $\mathrm{f}=3504 \mathrm{MHz}$

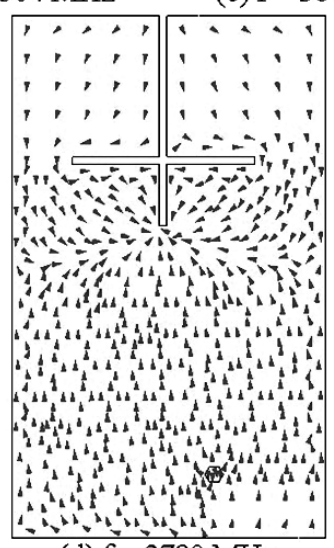

(d) $\mathrm{f}=3780 \mathrm{MHz}$

Fig. 5 (a) Input impedance plot and (b - d) surface current distribution over BW for plus shaped slot cut RMSA

Further based upon the above explanation for the dual band and broadband response of reported configurations, their similar prototypes were designed in $1000 \mathrm{MHz}$ frequency band. The patch dimension ' $\mathrm{L}$ ' as shown in Fig. 6(a) is selected such that its $\mathrm{TM}_{01}$ mode frequency is around 900 MHz. Further ' $\mathrm{W}$ ' is calculated using the same ' $\mathrm{L} / \mathrm{W}$ ' ratio as present in the reported equivalent RMSA. Thus for FR4 substrate, ' $\mathrm{L}$ ' and ' $\mathrm{W}$ ' is found to be 7.8 and $4.7 \mathrm{~cm}$, respectively. For these patch dimension, $\mathrm{TM}_{11}$ and $\mathrm{TM}_{02}$ mode frequencies are 1769 and $1830 \mathrm{MHz}$, respectively. To realize dual frequency response, rectangular slot is cut on the 
patch edge as shown in Fig. 6(a). The slot dimensions are taken to be in same proportion with respect to patch dimensions as that given in the reported configuration. In reported configuration, ratio of $1_{1} / \mathrm{L}$ is 0.4 , which gives slot length of $3.14 \mathrm{~cm}$ for $\mathrm{L}=7.8 \mathrm{~cm}$. For $\mathrm{w}_{1}=0.1 \mathrm{~cm}$, the simulated and measured dual frequency response is shown in Fig. 6(b). The simulated dual frequencies and BW's are 1632 and $1827 \mathrm{MHz}$ and 40 and $41 \mathrm{MHz}$, respectively. The measured dual frequencies and BW's are 1680 and $1890 \mathrm{MHz}$ and 37 and $40 \mathrm{MHz}$, respectively. This prototype shows similar radiation pattern characteristics at dual frequencies to that given by reported configuration. The fabricated prototype of the configuration is shown in Fig. 7(a).

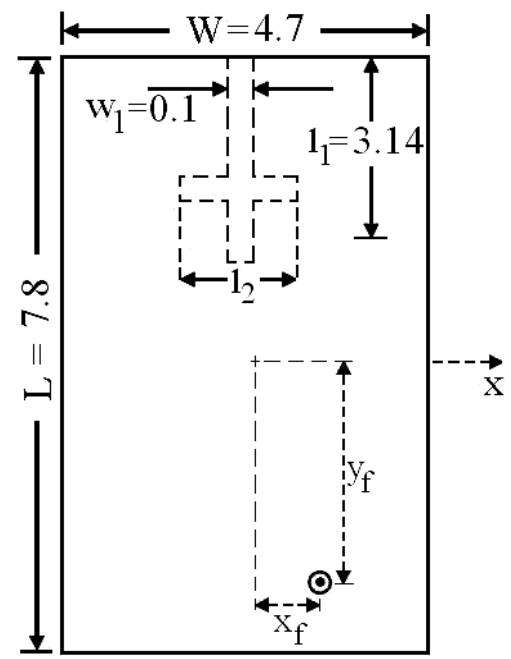

(a)

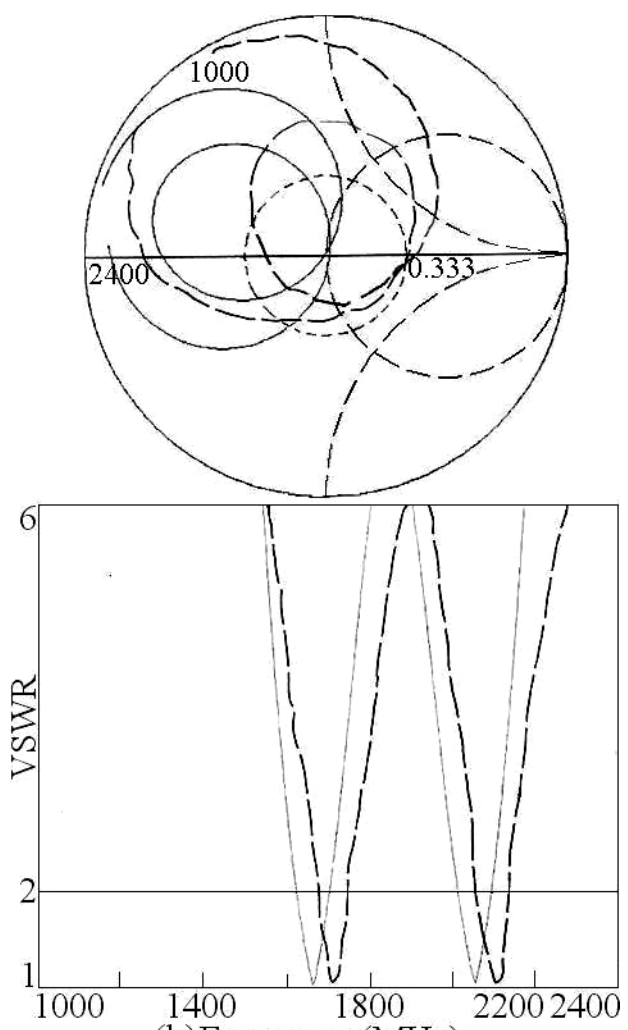

(b)Frequency $(\mathrm{MHz})$

Fig. 6 (a) Slot cut RMSA and (b) input impedance and VSWR plots for dual band RMSA, $(-)$ simulated, $(--)$ measured
Further to realize plus shaped slot, slot length ' $l_{2}$ ' as shown in Fig. 6(a) is cut inside the rectangular slot cut RMSA. In the reported configuration, ratio of $l_{2} / \mathrm{W}$ is 0.57 , which gives ' $l_{2}$ ' $=$ $2.7 \mathrm{~cm}$ for $\mathrm{W}=4.7 \mathrm{~cm}$. The optimum broadband response is realized for $\mathrm{l}_{2}=2.5 \mathrm{~cm}$ as shown in Fig. 7(b). The simulated BW is $96 \mathrm{MHz}(5.86 \%)$ whereas the measured BW is 100 $\mathrm{MHz}(5.98 \%)$. The fabricated prototype of the configuration is shown in Fig. 8. This configuration also shows similar radiation pattern characteristics to that given by reported configuration.

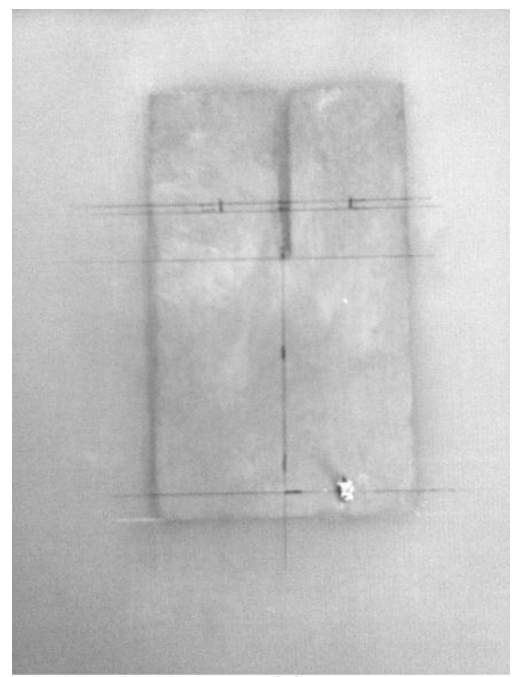

(a)

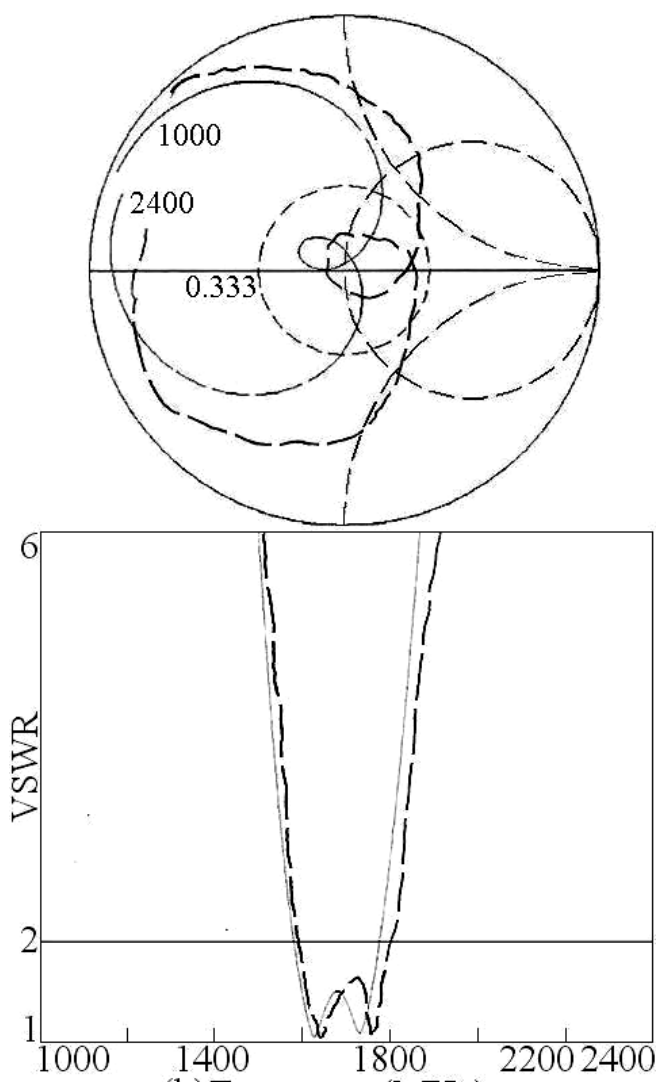

(b)Frequency $(\mathrm{MHz})$

Fig. 7 (a) Fabricated prototype of rectangular slot cut RMSA, (b) input impedance and VSWR plots for broadband plus shaped slot cut RMSA, (-) simulated, $(--)$ measured 


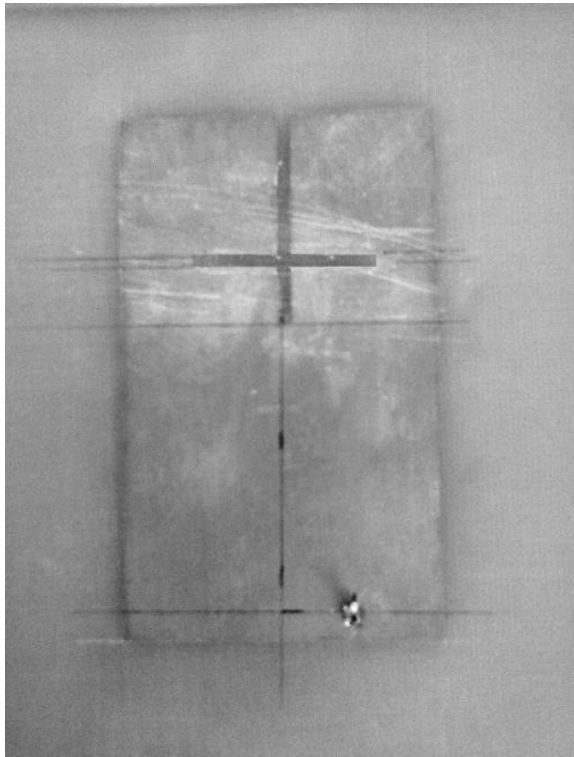

Fig. 8 Fabricated prototype of plus shaped slot cut RMSA

\section{CONCLUSIONS}

An analysis of reported dual band rectangular slot and broadband plus shaped slot cut RMSA is presented. The present designs of slot cut configurations were designed with respect to $\mathrm{TM}_{11}$ mode frequency of the equivalent RMSA. In rectangular slot cut RMSA, the slot reduces $\mathrm{TM}_{11}$ mode frequency and along with $\mathrm{TM}_{02}$ mode frequency yields dual frequency response. Further at first frequency, the dual band RMSA yields broadside radiation pattern whereas at second frequency it yields conical pattern. Further when additional rectangular slot is cut inside above rectangular slot, which completes plus shaped structure, it optimizes the input impedance as well as the frequencies of above modified $\mathrm{TM}_{11}$ and $\mathrm{TM}_{02}$ modes and realizes broadband response. Since modified $\mathrm{TM}_{02}$ mode is present towards higher frequencies of $\mathrm{BW}$, the radiation pattern is maximum in the end-fire direction with higher cross polar levels. Further by using the above analysis slot cut dual band and broadband configurations of RMSAs in $1000 \mathrm{MHz}$ frequency band $\left(\mathrm{TM}_{01}\right.$ mode frequency) are proposed. The dual band RMSA yields $\mathrm{BW}$ of $40 \mathrm{MHz}$ at modified $\mathrm{TM}_{11}$ and $\mathrm{TM}_{02}$ mode frequencies whereas plus shaped slot cut configuration yields $\mathrm{BW}$ of $100 \mathrm{MHz}(\sim 6 \%)$.

\section{REFERENCES}

[1] Kumar, G., and Ray, K. P. 2003, Broadband Microstrip Antennas, First Edition, USA, Artech House

[2] Bhartia, B., and Bahl, I. J. 1980, Microstrip Antennas, USA

[3] Garg, R., Bhartia, P., Bahl, I., and Ittipiboon, A., Microstrip Antenna Design Handbook, 2001, Artech House, USA.

[4] Wong, K. L. 2002. Compact and Broadband Microstrip Antennas, John Wiley \& sons, Inc., New York, USA

[5] Huynh, T., and Lee, K. F. 1995. Single-Layer SinglePatch Wideband Microstrip Antenna, Electronics Letters, vol. 31, no. 16, (August 1995), 1310-1312.

[6] Guo, Y. X., Luk, K. M., Lee, K. F., and Chow, Y. L. 1998. Double U-slot Rectangular Patch Antenna, Electronics Letters, vol. 34, 1805 - 1806

[7] Wong, K. L., and Hsu, W. H. 2001. A Broadband Rectangular Patch Antenna with a Pair of wide slits, IEEE Transactions on Antennas \& Propagation, Vol. 49, No. 9, (September 2001), 1345 - 1347.

[8] Yang, F., Zhang, X., Yc, X., and Sammi, Y. R. 2001. Wide-band E-shaped patch antennas for wireless communication, IEEE Transactions on Antennas \& Propagation, vol. 49, no. 7, (July 2001), $1094-1100$.

[9] Lee, K. F., Yang, S. L. S., Kishk, A. A., and Luk, K. M. 2010. The Versatile U-slot Patch, IEEE Antennas \& Propagation Magazine, vol. 52, no. 1, (February 2010), $71-88$.

[10] Denidni, T. A., and Hassaine, N. 2008. Broadband and high Gain E-shaped Microstrip antennas for high speed wireless networks, PIERS C, vol. 1, (2008), 105 -111 .

[11] Deshmukh, Amit A., Joshi, Apurva A., and Tirodkar, T., Broadband slot cut gap-coupled proximity fed Eshaped Microstrip Antenna, International Journal of Computer Application, vol. 68, no. 17, April 2013, 15 $-18$

[12] Sekra, P., Dubey, M., Shekhawat, S., Bhatnagar, D., Saxena, V. K., and Saini, J. S. 2011. Broadband Rectangular Patch Antenna with Orthogonal Crossed Slits, International Journal of Microwave and Optical Technology, vol. 6, no. 4, (2011), $179-184$.

[13] IE3D 12.1, 2004. Zeland Software, Freemont, USA 